Pacific Journal of Mathematics

INEQUALITIES FOR POLYNOMIALS WITH A PRESCRIBED
ZERO

JOHN D. DONALDSON AND QAZI IBADUR RAM 


\title{
INEQUALITIES FOR POLYNOMIALS WITH A PRESCRIBED ZERO
}

\author{
J. D. Donaldson AND Q. I. RahMaN
}

Let $\mathscr{P}_{n}$ denote the linear space of polynomials $p(z)=$ $\sum_{k=0}^{n} a_{k} z^{k}$ of degree at most $n$. There are various ways in which we can introduce norm $(\|\|)$ in $\mathscr{P}_{n}$. Given $\beta$ let $\mathscr{P}_{n, \beta}$ denote the subspace consisting of those polynomials which vanish at $\beta$. Then how large can $\|p(z) /(z-\beta)\|$ be if $p(z) \in \mathscr{P}_{n, \beta}$ and $\|p(z)\|=1$ ? This general question does not seem to have received much attention. Here the problem is investigated when (i) $\|p(z)\|=\max _{|z| \leqslant 1}|p(z)|$, (ii) $\|p(z)\|=$ $\left(1 / 2 \pi \int_{0}^{2 \pi}\left|p\left(e^{i \theta}\right)\right|^{2} d \theta\right)^{1 / 2}$

It was shown by Rahman and Mohammad [1] that if $p(z) \in \mathscr{P}_{n, 1}$ and $\max _{|z| \leqslant 1}|p(z)| \leqq 1$ then

$$
\max _{|z| \leqslant 1}|p(z) /(z-1)| \leqq n / 2 \text {. }
$$

We observe that if $p(z) \in \mathscr{P}_{n, \beta}$ and $\max _{|z| \leqslant 1}|p(z)|=1$ then $\max _{|z| \leqslant 1}|p(z) /(z-\beta)|$ can be greater than $n / 2$ if $\beta$ is arbitrary. For $n=1$ we may simply take $p(z)=z$. When $n>1$ we consider the polynomial

$$
p(z)=(n / 2)\left(n^{2}-1\right)^{-1 / 2}\left(1+z+z^{2}+\cdots+z^{n-1}\right)\left(z-1+2 n^{-2}\right) .
$$

If $z=e^{i \theta}$ then for $\cos \theta \leqq 1-2 n^{-2}$

$$
|p(z)| \leqq(1 / 2)\left|\left(1+z+z^{2}+\cdots+z^{n-1}\right)(z-1)\right| \leqq 1,
$$

and also for $\cos \theta \geqq 1-2 n^{-2}$

$$
\mid p(z))\left|\leqq n\left(n^{2}-1\right)^{-1 / 2}(n / 2)\right| z-1+2 n^{-2} \mid \leqq 1
$$

while

$$
\max _{|z|=1}\left|p(z) /\left(z-1+2 n^{-2}\right)\right|=\left(n^{2} / 2\right)\left(n^{2}-1\right)^{-1 / 2}>\frac{n}{2} .
$$

We note howevever that if $p(z) \in \mathscr{P}_{n, \beta}$ and $\max _{|z| \leqslant 1}|p(z)| \leqslant 1$, then

$$
\max _{|z|=1}|p(z) /(z-\beta)| \leqq(n+1) / 2
$$

Proof of inequality (2). Without loss of generality we may assume $\beta$ to be real and nonnegative. Put $p(z)=(z-\beta) q(z)$ and write 
$p^{*}(z)=(z-1) q(z) . \quad$ Then

$$
\left|p^{*}\left(e^{i \theta}\right) / p\left(e^{i \theta}\right)\right|=\left|\left(e^{i \theta}-1\right) /\left(e^{i \theta}-\beta\right)\right| \leqq 2 /(1+\beta)
$$

which gives us

$$
\max _{|z|=1}\left|p^{*}(z)\right| \leqq 2(1+\beta)^{-1} \max _{|z|=1}|p(z)| .
$$

From inequalities (1) and (4) we obtain

$$
\begin{aligned}
\max _{|z|=1}|q(z)| & \leqq(n / 2) \max _{|z|=1}\left|p^{*}(z)\right| \leqq n(1+\beta)^{-1} \max _{|z|=1}|p(z)| \\
& \leqq \frac{n+1}{2} \max _{|z|=1}|p(z)|
\end{aligned}
$$

provided $\beta \geqq(n-1) /(n+1)$.

For $\beta \leqq(n-1) /(n+1)$ we have

$$
\left|q\left(e^{i \theta}\right)\right|=\left|p\left(e^{i \theta}\right) /\left(e^{i \theta}-\beta\right)\right| \leqq(1-\beta)^{-1}\left|p\left(e^{i \theta}\right)\right| \leqq \frac{n+1}{2}\left|p\left(e^{i \theta}\right)\right|
$$

and hence

$$
\max _{|z|=1}|q(z)| \leqq \frac{n+1}{2} \max _{|z|=1}|p(z)|
$$

This completes the proof of inequality (2). Unfortunately, with the exception of $n=1$ the bound $(n+1) / 2$ does not appear to be sharp.

We now examine the $L^{2}$ analogue of the above problem. We prove the following theorem.

THEOREM. If $p(z)$ is a polynomial of degree $n$ such that $p(\beta)=0$ where $\beta$ is an arbitrary nonnegative number then

$$
\int_{0}^{2 \pi}\left|p\left(e^{i \theta}\right) /\left(e^{i \theta}-\beta\right)\right|^{2} d \theta \leqq\left(1+\beta^{2}-2 \beta \cos \left(\frac{\pi}{n+1}\right)\right)^{-1} \int_{0}^{2 \pi}\left|p\left(e^{i \theta}\right)\right|^{2} d \theta
$$

Proof of the theorem. Let us write

$$
p(z) /(z-\beta)=\alpha_{n-1} z^{n-1}+\alpha_{n-2} z^{n-2}+\cdots+\alpha_{1} z+\alpha_{0}, \alpha_{n-1} \neq 0 .
$$

Then

$$
p(z)=\alpha_{n-1} z^{n}+\left(\alpha_{n-2}-\beta \alpha_{n-1}\right) z^{n-1}+\cdots+\left(\alpha_{0}-\beta \alpha_{1}\right) z-\beta \alpha_{0} .
$$

We therefore have to consider the ratio

$$
R \equiv\left(\sum_{\nu=0}^{n-1}\left|\alpha_{\nu}\right|^{2}\right) /\left(\left|\alpha_{n-1}\right|^{2}+\sum_{\nu=0}^{n-1}\left|\alpha_{\nu-1}-\beta \alpha_{\nu}\right|^{2}+\beta\left|\alpha_{0}\right|^{2}\right) .
$$

Now 


$$
\begin{aligned}
R & \leqq\left(\sum_{\nu=1}^{n-1}\left|\alpha_{\nu}\right|^{2}\right) /\left(\left(1+\beta^{2}\right) \sum_{\nu=0}^{n-1}\left|\alpha_{\nu}\right|^{2}-2 \beta \sum_{\nu=1}^{n-1}\left|\alpha_{\nu}\right|\left|\alpha_{\nu-1}\right|\right) \\
& =1 /\left(1+\beta^{2}-2 \beta\left(\sum_{\nu=1}^{n-1}\left|\alpha_{\nu}\right|\left|\alpha_{\nu-1}\right|\right) /\left(\sum_{\nu=0}^{n-1}\left|\alpha_{\nu}\right|^{2}\right)\right) .
\end{aligned}
$$

Thus we require the maximum of the function

$$
f\left(\left|\alpha_{0}\right|,\left|\alpha_{1}\right|, \cdots,\left|\alpha_{n-1}\right|\right)=\left(\sum_{\nu=1}^{n-1}\left|\alpha_{\nu}\right|^{2}\right)^{-1}\left(\sum_{\nu=1}^{n-1}\left|\alpha_{\nu}\right|\left|\alpha_{\nu-1}\right|\right)
$$

with respect to $\left|\alpha_{0}\right|,\left|\alpha_{1}\right|, \cdots,\left|\alpha_{n-1}\right|$. It is clear that the maximum is less than 1.

If for some $\nu, \alpha_{\nu}=0$ and $j$ is the smallest positive integer such that $\alpha_{\nu-j}, \alpha_{\nu+j}$ are not both zero $\left(\alpha_{-1}, \alpha_{-2}\right.$, etc... are to be interpreted as zero) then

$$
\begin{aligned}
& f\left(\left|\alpha_{0}\right|,\left|\alpha_{1}\right|, \cdots,\left|\alpha_{\nu-1}\right|, 0,\left|\alpha_{\nu+1}\right|, \cdots,\left|\alpha_{n-1}\right|\right) \\
& \leqq f\left(\left|\alpha_{0}\right|,\left|\alpha_{1}\right|, \cdots,\left|\alpha_{\nu-1}\right|,\left|\alpha_{\nu}^{\prime}\right|,\left|\alpha_{\nu+1}\right|, \cdots,\left|\alpha_{n-1}\right|\right)
\end{aligned}
$$

provided

$$
\left|\alpha_{\nu}^{\prime}\right| \leqq\left(\left|\alpha_{\nu-j}\right|+\left|\alpha_{\nu+j}\right|\right) / f\left(\left|\alpha_{0}\right|,\left|\alpha_{1}\right|, \cdots,\left|\alpha_{\nu-1}\right|, 0,\left|\alpha_{\nu+1}\right|, \cdots,\left|\alpha_{n-1}\right|\right) \text {. }
$$

This implies that the maximum is not attained when one or more of the numbers $\left|\alpha_{\nu}\right|$ are zero.

On the other hand if one or more of the numbers $\left|\alpha_{\nu}\right|$ are allowed to be arbitrarily large the function $f\left(\left|\alpha_{0}\right|,\left|\alpha_{1}\right|, \cdots,\left|\alpha_{n-1}\right|\right)$ is bounded above by $(n-1) / n$.

Consider now the partial derivatives of $f$ with respect to the variables $\left|\alpha_{\nu}\right|$. For a local maximum we have to find $\left|\alpha_{0}\right|,\left|\alpha_{1}\right|, \cdots$, $\left|\alpha_{n-1}\right|$ such that

$$
\left\{\begin{array}{l}
\left(\sum_{\nu=0}^{n-1}\left|\alpha_{\nu}\right|^{2}\right) \frac{\partial f}{\partial\left|\alpha_{0}\right|}=\left|\alpha_{1}\right|-2 f\left|\alpha_{0}\right|=0, \\
\left(\sum_{\nu=0}^{n-1}\left|\alpha_{\nu}\right|^{2}\right) \frac{\partial f}{\partial\left|\alpha_{\mu}\right|}=\left|\alpha_{\mu+1}\right|+\left|\alpha_{\mu-1}\right|-2 f\left|\alpha_{\mu}\right|=0, \\
\left(\sum_{\nu=0}^{n-1}\left|\alpha_{\nu}\right|^{2}\right) \frac{\partial f}{\partial\left|\alpha_{n-1}\right|}=\left|\alpha_{n-2}\right|-2 f\left|\alpha_{n-1}\right|=0 .
\end{array}\right.
$$

Let us suppose that the required local maximum is $\lambda$. Since $\lambda<1$ we write $\lambda=\cos \gamma(\gamma \neq 0)$. Then from the first $n-1$ equations of the system (14) we obtain

$$
\left|\alpha_{\mu}\right|=U_{\mu}(\lambda)\left|\alpha_{0}\right|, \quad \mu=1,2, \cdots, n-1
$$

where $U_{\mu}(\lambda)=(\sin (\mu+1) \gamma) /(\sin \gamma)$ is the Chebyshev polynomial of the second kind of degree $\mu$ in $\lambda$. Using equations (15) the last equation of the system (14) gives us 


$$
\sin (n+1) \gamma=0 .
$$

The only solution of (16) which is consistent with all the numbers $\left|\alpha_{\nu}\right|$ being nonnegative is $\gamma=\pi /(n+1)$. Hence

$$
\lambda=\cos \left(\frac{\pi}{n+1}\right) \text {. }
$$

Since $\cos (\pi /(n+1)) \geqq(n-1) / n$ the required maximum of the function $f\left(\left|\alpha_{0}\right|,\left|\alpha_{1}\right|, \cdots,\left|\alpha_{n-1}\right|\right)$ is $\cos (\pi /(n+1))$. This immediately leads to the inequality (8).

We note that the polynomial

$$
p(z)=(z-\beta) \sum_{\nu=0}^{n-1} U_{\nu}\left(\cos \left(\frac{\pi}{n+1}\right)\right) z^{\nu}
$$

is extremal.

\section{REFERENCES}

1. Q. I. Rahman and Q. G. Mohammad, Remarks on Schwarz's lemma, Pacific J. Math. 23 (1967), 139-142.

Received January 19, 1971.

UNIVERSITY OF MONTREAL 


\section{PACIFIC JOURNAL OF MATHEMATICS}

\section{EDITORS}

\author{
H. SAMELSON \\ Stanford University \\ Stanford, California 94305

\section{R. HoвBY} \\ University of Washington \\ Seattle, Washington 98105
}

\section{J. DugundJI}

Department of Mathematics University of Southern California Los Angeles, California 90007

\author{
RichaRd ARENS \\ University of California \\ Los Angeles, California 90024
}

\section{ASSOCIATE EDITORS}
E. F. BECKENBACH
B. H. NEUMANN
F. WOLF
K. YoshidA

\section{SUPPORTING INSTITUTIONS}

\author{
UNIVERSITY OF BRITISH COLUMBIA \\ CALIFORNIA INSTITUTE OF TECHNOLOGY \\ UNIVERSITY OF CALIFORNIA \\ MONTANA STATE UNIVERSITY \\ UNIVERSITY OF NEVADA \\ NEW MEXICO STATE UNIVERSITY \\ OREGON STATE UNIVERSITY \\ UNIVERSITY OF OREGON \\ OSAKA UNIVERSITY
}

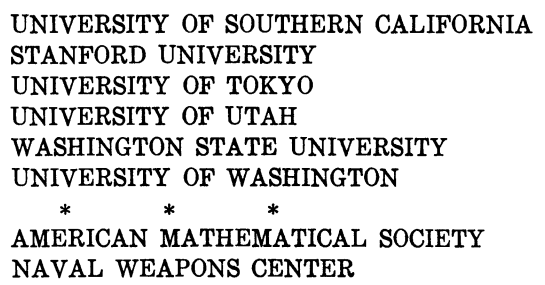

The Supporting Institutions listed above contribute to the cost of publication of this Journal, but they are not owners or publishers and have no responsibility for its content or policies.

Mathematical papers intended for publication in the Pacific Journal of Mathematics should be in typed form or offset-reproduced, (not dittoed), double spaced with large margins. Underline Greek letters in red, German in green, and script in blue. The first paragraph or two must be capable of being used separately as a synopsis of the entire paper. The editorial "we" must not be used in the synopsis, and items of the bibliography should not be cited there unless absolutely necessary, in which case they must be identified by author and Journal, rather than by item number. Manuscripts, in dup icate if possible, may be sent to any one of the four editors. Please classify according to the scheme of Math. Rev. Index to Vol. 39. All other communications to the editors should be addressed to the managing editor, Richard Arens, University of California, Los Angeles, California, 90024.

50 reprints are provided free for each article; additional copies may be obtained at cost in multiples of 50 .

The Pacific Journal of Mathematics is published monthly. Effective with Volume 16 the price per volume (3 numbers) is $\$ 8.00$; single issues, $\$ 3.00$. Special price for current issues to individual faculty members of supporting institutions and to individual members of the American Mathematical Society: $\$ 4.00$ per volume; single issues $\$ 1.50$. Back numbers are available.

Subscriptions, orders for back numbers, and changes of address should be sent to Pacific Journal of Mathematics, 103 Highland Boulevard, Berkeley, California, 94708.

PUBLISHED BY PACIFIC JOURNAL OF MATHEMATICS, A NON-PROFIT CORPORATION

Printed at Kokusai Bunken Insatsusha (International Academic Printing Co., Ltd.), 270, 3-chome Totsuka-cho, Shinjuku-ku, Tokyo 160, Japan. 


\section{Pacific Journal of Mathematics}

\section{Vol. 41, No. 2 December, 1972}

Tom M. (Mike) Apostol, Arithmetical properties of generalized Ramanujan sums .......................................... 281

David Lee Armacost and William Louis Armacost, On p-thetic groups ........ 295

Janet E. Mills, Regular semigroups which are extensions of groups .......... 303

Gregory Frank Bachelis, Homomorphisms of Banach algebras with minimal ideals ................................................ 307

John Allen Beachy, A generalization of injectivity .................. 313

David Geoffrey Cantor, On arithmetic properties of the Taylor series of rational functions. II.........................................

Václáv Chvátal and Frank Harary, Generalized Ramsey theory for graphs. III.

Small off-diagonal numbers .................................. 335

Frank Rimi DeMeyer, Irreducible characters and solvability of finite groups . . . . 347

Robert P. Dickinson, On right zero unions of commutative semigroups........ 355

John Dustin Donald, Non-openness and non-equidimensionality in algebraic

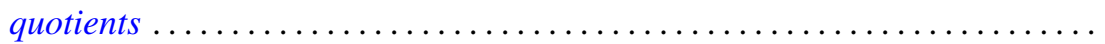

John D. Donaldson and Qazi Ibadur Rahman, Inequalities for polynomials with a prescribed zero ........................................ 375

Robert E. Hall, The translational hull of an $N$-semigroup ................ 379

John P. Holmes, Differentiable power-associative groupoids.............. 391

Steven Kenyon Ingram, Continuous dependence on parameters and boundary data for nonlinear two-point boundary value problems .

Robert Clarke James, Super-reflexive spaces with bases ..........

Gary Douglas Jones, The embedding of homeomorphisms of the plane in

continuous flows...............................

Mary Joel Jordan, Period $H$-semigroups and $t$-semisimple periodic

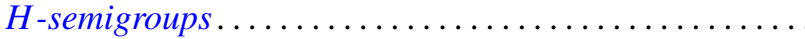

Ronald Allen Knight, Dynamical systems of characteristic 0

Kwangil Koh, On a representation of a strongly harmonic ring by sheaves...

Hui-Hsiung Kuo, Stochastic integrals in abstract Wiener space. ..

Thomas Graham McLaughlin, Supersimple sets and the problem of extending a

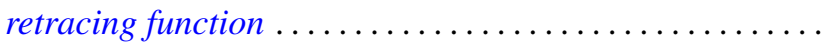

William Nathan, Open mappings on 2-manifolds .

M. J. O'Malley, Isomorphic power series rings

Sean B. O'Reilly, Completely adequate neighborhood systems and metrization

Qazi Ibadur Rahman, On the zeros of a polynomial and its derivative...

Russell Daniel Rupp, Jr., The Weierstrass excess function ..

Hugo Teufel, A note on second order differential inequalities and functional

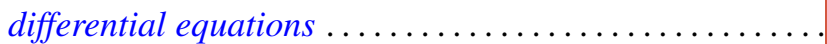

M. J. Wicks, A general solution of binary homogeneous equations over free 